\title{
Elaboration of triplex PCR for detection of selected viral infections in waterfowl
}

\author{
Wojciech Kozdruń, Hanna Czekaj, Natalia Styś-Fijoł, \\ Karolina Piekarska, Jowita Samanta Niczyporuk \\ Department of Poultry Diseases, \\ National Veterinary Research Institute, 24-100 Puławy, Poland \\ wkozdrun@piwet.pulawy.pl
}

Received: July 17, $2019 \quad$ Accepted: November 22, 2019

\begin{abstract}
Introduction: Viral infections are the greatest threat to waterfowl and cause significant economic losses. Diagnosis and differentiation of three goose viruses is difficult in the field and often requires laboratory confirmation. Therefore, the aim of the study was to develop a triplex PCR and optimise its parameters for simultaneous detection of DNA of goose parvovirus (GPV), goose polyomavirus (GHPV), and goose circovirus (GoCV). Material and Methods: The DNA of viruses isolated from field cases from the National Veterinary Research Institute's own collection was used for the study. The primer attachment temperature, the number of reaction cycles, and the Taq DNA polymerase and $\mathrm{Mg}^{2+}$ concentrations were optimised. The sensitivity and specificity of this triplex PCR was also determined. Results: Based on the obtained results, triplex PCR parameters were optimised for simultaneous detection of DNA of GPV, GHPV, and GoCV in one sample. The following PCR products of the expected size were obtained: GPV DNA of 806 bp, GoCV DNA of 571 bp, and GHPV DNA of 180 bp. Conclusion: The developed triplex PCR method proved to be useful for simultaneous detection of infections with three waterfowl viruses and will be used in relevant laboratory diagnostics.
\end{abstract}

Keywords: goose parvovirus, goose polyomavirus, goose circovirus, triplex PCR.

\section{Introduction}

Geese are one of the best-known Polish poultry products on the world market, and Poland is the secondlargest exporter of goose products in Europe after Hungary. Last year, nearly 8 million geese were raised in Poland, and around 6 million birds were slaughtered for meat.

Farms with populations of several thousand geese and dense concentrations of birds in a limited area pose a serious threat of epidemics, from which significant economic losses can ensue.

The most serious threat to goslings and adult geese are viral diseases, among which are Derzsy's disease (DD) caused by goose parvovirus (GPV), haemorrhagic nephritis and enteritis syndrome of geese (HNEG), the aetiological factor of which is goose haemorrhagic polyomavirus (GHPV), and goose circovirus infections (GoCV) (1-4, 6). The correct diagnosis and differentiation of these three diseases on the basis of clinical symptoms and anatomopathological changes are difficult, and sometimes even impossible, and therefore they must be confirmed in the laboratory. Very often, laboratory diagnosis of these diseases is based on methods using goose embryos, which are available only during the laying period lasting from February to the end of June, and the costs of such tests are very high. Therefore, the aim of the study was to standardise the parameters of amplification in a triplex PCR, which will allow simultaneous detection of genetic material of GPV, GHPV, and GoCV in the shortest possible time and in one reaction.

\section{Material and Methods}

Reference DNA. The DNA from two strains of GPV, GHPV, and GoCV was used for the study. It was obtained from the collection of the Department of Poultry Diseases of the National Veterinary Research Institute in Pulawy. Viruses were isolated from sick birds from field cases. As a positive control, isolates of 
GPV DNA, DNA of a GHPV strain, and GoCV DNA provided by Dr. Vilmos Palya (Ceva Phylaxia, Budapest, Hungary) were used. As a negative control in the PCR, use was made of cellular DNA isolated from uninfected goose embryo fibroblasts (GEF) cells.

Oligonucleotides (primers) for PCR. The primers were designed in the Primer3Plus computer programme (http://www.bioinformatics.nl/cgibin/primer3plus/prim er3plus.cgi), and primers with sequences complementary to the conserved fragments of the virus genome were derived. For GPV the selected sequence was the region of the genome encoding the VP1 protein: VPD1 - 5'-CCG GGT TGC AGG TAC-3' and VPD2 5'-AGC TAC AAC AAC CAC ATC-3'; for GHPV it was also the genomic region encoding this protein: GPOL1 - 5'-GAG GTT GTT GGA GTG ACC ACA ATG-3' and GPOL2 - 5'-ACA ACG GTG CAA TTC CAA GGG TTC-3'; and the CVP1 protein-encoding region was appropriate for GoCV: GCV1 - 5'-TAA ATG CGA GTT TGA TGT GTC T-3' and GCV2 5'-CAT TTA ACC CCT TCC AAA GAG T-3'.

Triplex PCR optimisation. The reaction was optimised in a gradient thermocycler (Biometra, Göttingen, Germany) and in a reaction mixture containing $5 \mu \mathrm{l}$ of PCR buffer $(500 \mathrm{mM}$ of $\mathrm{KCl}, 100 \mathrm{mM}$ of Tris-HCl, and Triton X 100), $2 \mu$ l of deoxynucleotide mixture $(0.2 \mathrm{mM}), 2 \mu \mathrm{l}$ of each primer (10 $\mathrm{mM}$ each $), 2$ $\mu \mathrm{l}$ of isolated DNA, $1 \mu \mathrm{l}$ Taq DNA polymerase (Euro), and $11 \mu \mathrm{l}$ of PCR water. The following parameters were optimised: number of cycles (27 to 37$)$, the primer attachment temperature $\left(45^{\circ} \mathrm{C}\right.$ to $\left.65^{\circ} \mathrm{C}\right)$, and concentrations of Taq DNA polymerase (1 U and $2 \mathrm{U}$ ) and $\mathrm{Mg}^{2+}$.

Determination of triplex PCR specificity. DNA of the Muscovy duck parvovirus (MDPV) and DNA of the duck enteritis herpesvirus (DEHV) were used.

Determination of triplex PCR sensitivity. The DNA of the GPV strain obtained from Dr. Vilmos Palya was used at concentration of $223 \mathrm{ng} / \mu \mathrm{l}$ determined using a nanophotometer. A series of tenfold dilutions was prepared.

Electrophoresis of PCR products. The triplex PCR products were analysed by electrophoretic separation on a $2 \%$ agarose gel for $1 \mathrm{~h}$ at $120 \mathrm{~V}$. After electrophoresis, the size of the obtained triplex PCR reaction products was compared to the DNA bulk standard. The size of the expected triplex PCR products was 806 bp for GPV, 180 bp for GHPV, and 571 bp for GoCV.

\section{Results}

In the first stage of the study, the optimal concentration of $\mathrm{Mg}^{2+}$ was determined. The following concentrations of $\mathrm{Mg}^{2+}$ were used: $1 \mathrm{mM}, 3 \mathrm{mM}, 5 \mathrm{mM}$, $7.5 \mathrm{mM}$, and $10 \mathrm{mM}$. At the concentrations of $10 \mathrm{mM}$, $7.5 \mathrm{mM}$, and $5 \mathrm{mM}$, no positive triplex PCR results were obtained. However, when reacting concentrations of
$1 \mathrm{mM}$ and $3 \mathrm{mM}$, a positive triplex PCR result was obtained, and at the $3 \mathrm{mM}$ concentration no additional triplex PCR products, so-called dimers, were noted. A concentration of $3 \mathrm{mM} \mathrm{Mg}^{2+}$ was used for further investigations.

The appropriate primer attachment temperature was then determined. The following temperatures were used: $45^{\circ} \mathrm{C}, 50^{\circ} \mathrm{C}, 52^{\circ} \mathrm{C}, 55^{\circ} \mathrm{C}, 60^{\circ} \mathrm{C}$, and $65^{\circ} \mathrm{C}$. At $65^{\circ} \mathrm{C}$, no triplex $\mathrm{PCR}$ product was obtained. In the temperature range of $45^{\circ} \mathrm{C}-55^{\circ} \mathrm{C}$, apart from triplex PCR products, several unspecific dimer products were yielded. Specific and single triplex PCR products were produced at $60^{\circ} \mathrm{C}$, which was chosen as the subsequent temperature parameter.

In the next stage of the study, the number of reaction cycles was optimised among the alternatives of $27,30,35$, and 37 . A positive reaction was only achieved in the case of 37 cycles. PCR products were also obtained in 35 cycles; however, they were not products of the expected size. The 37-cycle reaction was used for the further studies.

The optimal Taq concentration of the DNA polymerase was then selected. A positive reaction was obtained at $1 \mathrm{U}$ concentration, which was therefore established for the continuation of the optimisation.

In the final stages, the sensitivity and specificity of the developed triplex PCR reaction were determined. The sensitivity of the reaction was determined at $5.5 \mathrm{ng} / \mu \mathrm{l}$ DNA.

Triplex PCR products of the expected size were obtained when GPV, GHPV, and GoCV DNA were the subjects, although no reaction products were observed in the samples of MDPV DNA or DVE DNA.

In conclusion, based on the results, optimisation of the triplex PCR parameters for simultaneous detection of DNA of GPV, GHPV, and GoCV was achieved. These optimised parameters are presented in Table 1 , and the correct electrophoresis separation is shown in Fig. 1.

Table 1. Optimal parameters of triplex PCR

\begin{tabular}{ll}
\hline Parameter & Volume of parameter \\
\hline Concentration of $\mathrm{Mg}^{2+}$ & $3 \mathrm{mM}$ \\
\hline Temperature of primers & $60^{\circ} \mathrm{C}$ \\
\hline Number of cycles & 37 \\
\hline Concentration of Taq polymerase DNA & $1 \mathrm{U}$ \\
\hline
\end{tabular}

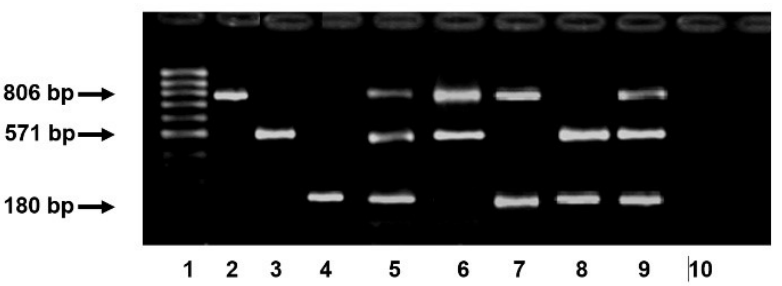

Fig. 1. Results of electrophoresis of optimal triplex PCR for detection of DNA of GPV, GHPV, and GoCV

Lanes: 1 - DNA marker; 2 - GPV; 3 - GoCV; 4 - GHPV; 5 - GPV, GoCV, GHPV; 6 - GPV, GoCV; 7 - GPV, GHPV; 8 - GoCV, GHPV; 9 - GPV, GoCV, GHPV; 10 - uninfected GEF (negative control) 


\section{Discussion}

Molecular biological methods, and in particular the amplification reaction together with its variants, have been widely used for several years, also in the diagnosis of poultry diseases, a difficulty concerning which is the lack of diagnostic kits on the market. Another problem is the seasonality of geese or duck embryos used for diagnosing waterfowl diseases.

In recognition of this situation, research was undertaken to optimise the triplex PCR performance parameters for simultaneous detection of goose parvovirus, goose circovirus, and goose polyomavirus. It should be noted that these three infections are diagnosed differentially and are currently causes of significant economic losses in large scale poultry production.

So far, few authors have undertaken trials to optimise poultry disease molecular diagnostic methods with strong focus on simultaneous detection of genetic material of several aetiological factors. In 2013, Chen et al. (1) presented the results of studies on the optimisation of multiplex PCR for the simultaneous detection of parvovirus, paramyxovirus, herpesvirus, and adenovirus in geese. In their research, they used samples obtained from birds suspected of having these infections. They demonstrated the high usefulness of the developed method for the diagnosis of infestations of those four viruses, which the results obtained in the case of our own developed triplex PCR method likewise demonstrate. The above publication is the only paper related to multiplex PCR in poultry available in the literature (1).

However, other authors have optimised the amplification parameters for single detection of viral infections in poultry (2-4). Leon et al. (4) presented the results of research on the use of real-time PCR to detect the genetic material of goose polyomavirus. They used samples collected from 15-week-old geese and geese being reared. Their results confirmed the significant occurrence of the infections in goose flocks. This was also confirmed by the results of our research in which the triplex PCR method was used (unpublished data).

For comparison of molecular biology methods, Woźniakowski et al. (5) presented the results of research on the application of the loop-mediated isothermal amplification (LAMP) method for the detection of circovirus infections. The authors showed the usefulness of this method, as well as that of the developed triplex PCR reaction for the diagnosis of goose circovirus infection. However, a slight advantage of the LAMP method over triplex PCR is its possibility to be performed without specialised laboratory equipment, i.e. in a water bath. Similar results were obtained by JinLong et al. (2) regarding the application of the LAMP method for the detection of goose parvovirus infections.

In the summary, it should be clearly stated that the developed method is original and sizeably supplements the choices in diagnosis of poultry diseases. This method largely eliminates limitations of both cost and the availability of a sufficient amount of material for testing, and also significantly shortens the time of analysis in comparison to individual amplification reactions detecting particular viruses.

Conflict of Interests Statement: The authors declare that there is no conflict of interests regarding the publication of this article.

Financial Disclosure Statement: The study was financed by the statutory activity of the National Veterinary Research Institute.

Animal Right Statement: None required.

\section{References}

1. Chen Z., Li C., Li G., Yu H., Jiang Y., Yan L., Meng C., Zhou Y., Tong G., Liu G.: Rapid diagnosis of goose viral infections by multiplex PCR. J Virol Methods 2013, 191, 101-104.

2. JinLong Y., Riu Y., AnChun C., MingShu W., LiZhi F., SongQuan Y., SuHui Z., Liu Y., ZhuYong X.: A simple and rapid method for detection of goose parvovirus in the field by loopmediated isothermal amplification. Virol J 2010, 7, 14-20.

3. Johne R., Wittig W., Fernandez-de-Luco D., Hofle U., Muller H.: Characterization of two novel polyomaviruses of birds by using multiply primed rolling-circle amplification of their genomes. J Virol 2006, 80, 3523-3531.

4. Leon O., Corrand L., Ngoc Bich T., Le Minor O., Lemaire M., Guerin J.L.: Goose hemorrhagic polyomavirus detection in geese using real-time PCR assay. Avian Dis 2013, 57, 797-799.

5. Woźniakowski G., Kozdruń W., Samorek-Salamonowicz E.: Loop-mediated isothermal amplification for the detection of goose circovirus. Virol J 2012, 9, 110-121. 